\title{
Código florestal e aplicações práticas na pequena propriedade rural
}

\author{
Forest code and practical applications in small farm
}

\author{
Diego Balestrin', Rafaelo Balbinot ${ }^{2}$, Jaqueline Valerius ${ }^{3}$ \\ 'Eng. Florestal, Mestrando do curso de Engenharia Ambiental da Universidade Federal de Santa Maria, campus sede \\ ${ }^{2}$ Eng. Florestal, Prof. Dr. do Departamento de Engenharia Florestal da Universidade Federal de Santa Maria, \\ campus de Frederico Westphalen, RS. \\ ${ }^{3}$ Acadêmica do Curso de Engenharia Florestal da Universidade Federal de Santa Maria, campus de Frederico Westphalen, RS.
}

\section{Resumo}

$\mathrm{Na}$ atualidade, as questões ambientais estão cada vez mais presentes no dia a dia da sociedade, sendo necessário gerar bens e serviços respeitando e preservando o meio ambiente, pois o desenvolvimento econômico de um país é fundamental para o bem estar e melhoria nas condições de vida da população, e esta qualidade de vida somente é possível com um meio ambiente equilibrado e saudável. Na grande maioria das propriedades rurais, não somente nos municípios em questão neste trabalho, mas também em todo o estado do Rio Grande do Sul e no país como um todo, há um descumprimento do Código Florestal vigente, seja ele não aplicado por falta de conhecimento da população, descaso, ou até mesmo por falta de fiscalização dos órgãos ambientais. Foram mapeados os diferentes usos do solo de propriedades rurais situadas na região do Médio Alto Uruguai, estado do Rio Grande do Sul, e verificado sua adequação ou não ao Código Florestal, analisando, assim, o efeito do seu cumprimento sobre a utilização do solo em pequenas propriedades rurais. As avaliações deste trabalho mostram a verdadeira realidade da agricultura minifundiária da região, quais aplicações do código que causaram maiores mudanças nas propriedades e seus impactos na propriedade, permitindo assim, um futuro trabalho baseado nos fatores que precisam ser melhorados e corrigidos em cada propriedade para as mesmas estarem em dia com o Código Florestal vigente.

Palavras Chave: Lei 12.651/2012, Área de Preservação Permanente, Reserva Legal.

\begin{abstract}
Nowadays, environmental issues are increasingly present in the everyday life of society, so it is necessary to generate goods and services respecting and preserving the environment, because the economic development of a country is fundamental for the well-being, and improvement in living conditions of the population, and this life quality is only possible with a healthy and balanced environment. In the vast majority of rural properties, not only in the municipalities concerned in this research, but also throughout the state of Rio Grande do Sul and in the country as a whole, there is a violation in the current Forestry Code, is it not applied for lack of knowledge from the population, neglect, or even through lack of supervision of environmental agencies. Different soil uses in rural properties from the Médio Alto Uruguai region, in the state of Rio Grande do Sul, were mapped, and it was found its suitability or not suitability to the forestry code, analyzing the effect of its fulfillment, on land use in small rural properties. The evaluations of this work show the true reality of small-scale agriculture in the region, which are the applications of the code that caused major changes in the properties, and their impacts on the property, thus, a future work based on factors that need to be improved and corrected on each property, for the same being up to date with the current Forestry Code. Keywords: Law 12.651/2012, permanent preservation area, legal reserves.
\end{abstract}




\section{INTRODUÇÃO}

As Áreas de Preservação Permanente (APP's) e de Reserva Legal (RL) são os principais instrumentos da Lei $\mathrm{n}^{\circ} 12.651 / 2012$ (BRASIL, 2012), assim como eram da Lei $n^{\circ} 4.771 / 1965$ (BRASIL, 1965). Deve-se ter em mente a classificação como APP independe da presença de vegetação, e que a RL é obrigatória para todas as propriedades rurais e sua percentagem prevista varia conforme o bioma do local analisado.

A partir destes fatos e conforme o último censo agropecuário realizado no Rio Grande do Sul (IBGE, 2006), o estado possui 416.976 unidades agropecuárias que em sua grande maioria pertencem a pequenos e médios proprietários rurais. Estes dependem (na maioria dos casos), unicamente, da agricultura como forma de renda e tendem a aproveitar ao máximo suas áreas para a atividade produtiva como forma de compensar o seu tamanho, o que muitas vezes causa uma pressão maior e consequentemente redução da vegetação nativa existente na mesma.

Por estas áreas sofrerem cada vez mais influência direta das atividades humanas sobre seus elementos, a Lei $\mathrm{n}^{\circ} 12.651 / 12$ (BRASIL, 2012) vem como um instrumento para controle das atividades de potencial impacto ao meio ambiente e aquelas que possam vir a prejudicar a qualidade deste para a atual e futura geração. Cabe ressaltar que o CFB prevê uma série de leis voltadas exclusivamente à pequena propriedade rural, $\mathrm{o}$ que revela a importância e a valorização destes no cenário atual, situação que não ocorria ou não era vivenciada na aplicação prática da antiga legislação.

Diante do novo cenário criado pela aprovação da Lei $n^{\circ}$ 12.651/12 (BRASIL, 2012), surge a necessidade de uma análise criteriosa da mesma e de seus impactos. Esta Lei trouxe novos conceitos e situações específicas cuja compreensão por parte dos profissionais e entidades responsáveis por sua aplicação é imprescindível, a fim de evitar diferentes interpretações que poderiam causar conflitos entre proprietários e os órgãos ambientais.

Pouco se conhece sobre o real impacto ambiental e social da aplicação desta lei nas propriedades e sobre a possibilidade de harmonizar as exigências de preservação e conservação com necessidade de melhores condições de vida na pequena propriedade rural. $\mathrm{O}$ presente trabalho tem o objetivo analisar uma amostra de propriedades rurais na Região do Médio Alto Uruguai Gaúcho e verificar qual o impacto da aplicação da Lei n ${ }^{\circ} 12.651 / 2012$ sobre a utilização do solo.

\section{MATERIAL E MÉTODOS}

As propriedades rurais analisadas estão localizadas na bacia hidrográfica do Rio da Várzea, na região hidrográfica do Rio Uruguai, a qual possui uma área de $9.463 \mathrm{~km}^{2}$. Seus principais formadores são os rios da Várzea e Guarita (FEPAM, 2013).

Situadas geograficamente ao noroeste do estado do Rio Grande do Sul, a região do Médio Alto Uruguai é caracteriza pelo seu relevo com superfícies irregulares e cotas altimétricas que variam entre 400 a $800 \mathrm{~m}$, estas formas de relevo não permitem mecanização plena da superfície agrícola (PIRAN, 2001). A população rural representa $45,2 \%$ da região e é caracterizada por pequenas unidades produtivas com uma média de 16 hectares (COREDEs, 2012).

As principais atividades econômicas desenvolvidas são a suinocultura, bovinocultura, cultivo de soja, milho, trigo e fumo. Além disso, esta região apresenta vários problemas ambientais relacionados com a descarga de efluentes de dejetos suínos e de aves sem tratamento em corpos hídricos, bem como uma boa parte do esgoto doméstico (FEPAM, 2013).

$\mathrm{Na}$ região, predominam solos minerais, pouco profundos, suscetíveis a erosão, moderadamente drenados, ácidos e com elevados teores minerais primários (Brunizem avermelhado) associados a solos pouco desenvolvidos, rasos, geralmente bem drenados e com restrições ao uso agrícola (Litólicos). Ocorrem ainda solos profundos, ácidos, com elevados teores de alumínio e apresentando problemas de fertilidade devido à pobreza de elementos nutritivos (Latossolo) (RÜCKERT et al., 1999). O solo é argiloso, pobre em quartzo, rico em ferro e manganês, cor vermelho-escuro, com pouca profundidade média, drenagem rápida e muito suscetível à erosão (STRECK et al.2008).

As propriedades foram selecionadas a partir do interesse do proprietário e de seu enquadramento como pequena propriedade rural, de acordo com o Art. $n^{\circ}$ XX da Lei $n^{\circ} 12.651 / 2012$ (BRASIL, 2012).

Para o georreferenciamento da propriedade, bem como a identificação dos seus diferentes usos do solo, foram percorridos os limites, divisas, benfeitorias, açudes, pastagens, área agricultável, fruticultura, cursos d'água, mata nativa, entre outros, existentes na mesma.

Foram utilizados equipamentos do curso de Engenharia Florestal (UFSM/CESNORS), entre eles: um GPS de navegação (Garmin 76 CSx), trena e caderneta de campo. Foram demarcados e 
anotados os limites e divisas de cada propriedade rural, bem como a existência de nascentes, cursos d'água, florestas nativas, plantações agrícolas ou florestais, benfeitorias entre outros.

Estas características e usos do solo foram cadastrados para posterior cálculo das respectivas áreas em hectares com o software TrackMaker -PRO versão 3.5.

\section{RESULTADOS}

A média do tamanho das propriedades analisadas foi de 16,5 ha, o que caracteriza a agricultura da região formada por pequenas propriedades rurais de base familiar. Todos os agricultores visitados demonstraram-se dispostos e interessados nas questões comentadas sobre a adequação ambiental, porém pelo fato de suas propriedades serem pequenas, mostrava-se clara a preocupação destes com a "redução de suas áreas agricultáveis". Este receio prevalecia tanto para a Lei anterior, $\mathrm{n}^{\circ} 4.771 / 65$ (antigo CFB), quanto para a atual $\mathrm{n}^{\circ} 12.651 / 12$, atentos ao fato que nenhum dos proprietários conhecia a Lei adequadamente.

A seguir é apresentada a Figura 1, onde foi realizada uma comparação entre as propriedades estudadas no tocante a aplicação das Leis $\mathrm{n}^{\circ}$ 4.771/65 (antigo CFB) e Lei ${ }^{\circ} 12.651 / 12$ (novo CFB) bem como analisadas as diferenças percentuais das mesmas no tocante à APP, RL caso as mesmas se adequassem ás respectivas lei Com a aplicação da Lei ${ }^{\circ}$ 4.771/65 (BRASIL, 1965), observou-se que $90 \%$ das propriedades estavam em desacordo com a Lei. Apesar disto, em termos percentuais, para poder tratar das 10 propriedades, os acréscimos das áreas de APP e RL eram de 2,4 e $4,2 \%$ ( 0,9 ha) respectivamente.
A partir da aplicação da Lei $n^{\circ} 12.651 / 12$, houve a redução do número de propriedades em desacordo (30\%). Com esta nova lei, as pequenas propriedades rurais, com seus diferentes usos do solo, tiveram maior facilidade de adequação legal. No caso das APP's, a aplicação da Lei ${ }^{\circ}$ $12.651 / 2012$ irá exigir em média $50 \mathrm{~m}^{2}$ por propriedade. Referente às RL's, observou-se que não houve mudança no uso do solo nas propriedades analisadas, permanecendo a média de $13,8 \%$. $\mathrm{Na}$ Tabela 2, são observados e comparados os resultados médios obtidos referentes a área total das propriedades analisadas, bem como seus respectivos percentuais no tocante ás APP's e RL's antes e depois da aplicação da Lei $\mathrm{n}^{\circ}$ 12.651/12.

Analisando as dez propriedades, observou-se que $70 \%$ destas apresentaram situação regular com a Lei $\mathrm{n}^{\circ}$ 12.651/12 (BRASIL, 2012), não precisando de nenhum tipo de alteração do uso do solo, sendo que as três propriedades que não estão de acordo com o código vigente são devido à falta de cobertura vegetal em nascentes e falta de vegetação nas áreas ripárias em alguns locais ao longo dos cursos hídricos, porém com mínimas alterações do uso do solo nestas propriedades as mesmas passam a estar em dia com a legislação vigente.

Nas propriedades estudadas, observou-se que com a implantação da Lei $\mathrm{n}^{\circ}$ 12.651/12, a redução da área para agricultura foi mínima. Isto demonstra que com a nova Lei as mudanças nos usos do solo serão não significativas comparadas com as mudanças que ocorreriam caso fosse implantado o antigo CFB (Lei $\mathrm{n}^{\circ} 4.771 / 65$ ).

Em termos numéricos, com a Lei $\mathrm{n}^{\circ}$ 4.771/1965 haveria uma redução média na área agricultável das propriedades de 7,8\% (1,3 ha) porém, com a Lei $\mathrm{n}^{\circ} 12.651 / 12$ a redução média

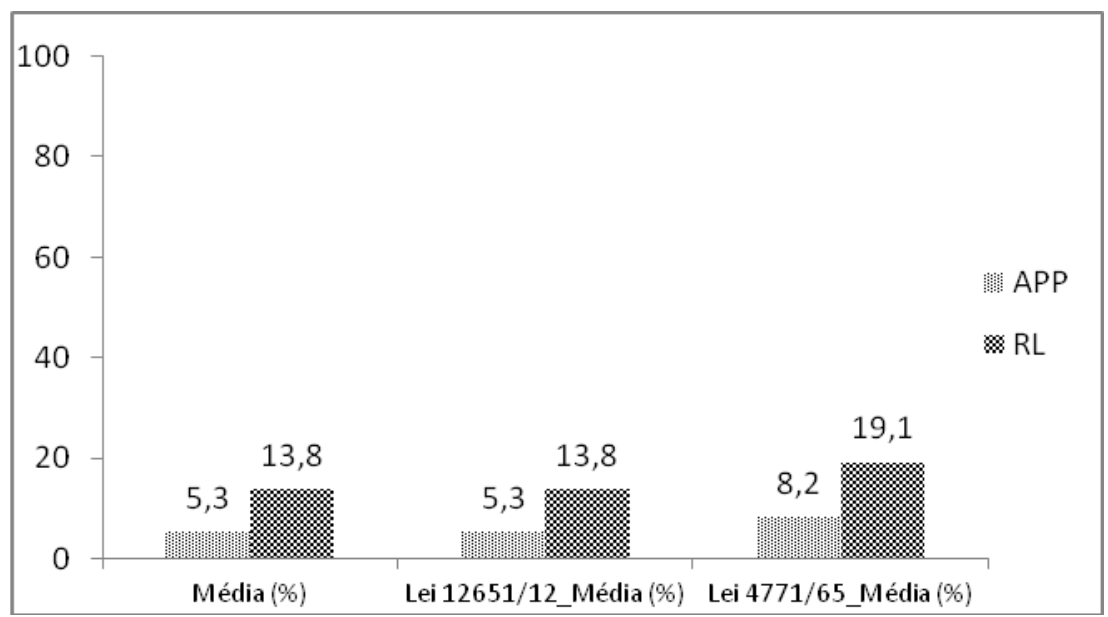

Figura 1: Comparação do percentual médio de mudanças ocorridas nas APP's e nas RL's com a aplicação das Leis $\mathrm{n}^{\circ} 12.651 / 12 \mathrm{e}$ 4.771/65(revogada), em função da média atual destes usos nas propriedades analisadas. 
Tabela 2: Características observadas em cada propriedade analisada referente à aplicação da Lei $\mathrm{n}^{\circ}$ 12.651/12.

\begin{tabular}{|c|c|c|c|c|c|}
\hline \multirow{2}{*}{ Propriedade } & \multirow{2}{*}{ Área total (ha) } & \multicolumn{2}{|c|}{ Antes (\%) } & \multicolumn{2}{c|}{ Depois (\%) } \\
\cline { 3 - 6 } & & $\mathbf{A P P}$ & $\mathbf{R L}$ & $\mathbf{A P P}$ & $\mathbf{R L}$ \\
\hline 1 & 12,2 & 8,2 & 8,2 & 8,2 & 8,2 \\
\hline $2^{*}$ & 11,3 & 0 & 18,6 & 0,8 & 18,6 \\
\hline $3^{*}$ & 6,3 & 2 & 21,8 & 2,15 & 21,8 \\
\hline 4 & 18,6 & 6,4 & 6,2 & 6,4 & 6,2 \\
\hline 5 & 26,7 & 1,8 & 3,0 & 1,8 & 3,0 \\
\hline 6 & 23,8 & 0,0 & 15,1 & 0,0 & 15,1 \\
\hline 7 & 17,1 & 15,2 & 0,4 & 15,2 & 0,4 \\
\hline $8^{*}$ & 14,8 & 14,3 & 21,6 & 14,4 & 21,6 \\
\hline 9 & 21,8 & 3,9 & 4,6 & 3,9 & 4,6 \\
\hline 10 & 12,9 & 1,0 & 38,3 & 1,0 & 38,3 \\
\hline
\end{tabular}

*Propriedades em desacordo com a Lei n ${ }^{\circ}$ 12.651/12

será de apenas 3,27\%, ou seja, 0,54 ha. Esta situação demonstra que além da redução de propriedades em desacordo com a Lei vigente, as mudanças de uso do solo são de baixo impacto.

\section{DISCUSSÃO}

Para entender e contextualizar as situações encontradas nas 10 propriedades estudadas é necessário ter em mente os novos conceitos trazidos pela atual Lei. O conceito de pequena propriedade rural (PPR), ou posse rural familiar pode ser observado no Art. $3^{\circ}$ da Lei ${ }^{\circ} 11.326$, de 24 de julho de 2006 (BRASIL, 2006) como sendo uma área não superior a 4 módulos fiscais (variável para cada município) e que utilize predominantemente mão de obra da própria família na execução das atividades desenvolvidas na mesma, obtendo renda a partir destas atividades. Conforme o exposto e analisando a região, pode-se observar que grande parte das propriedades existentes possui área inferior a quatro módulos fiscais. Para a região analisada um módulo fiscal representa, em média, 20 hectares (INCRA, 1980), ou seja, cada propriedade para se enquadrar na categoria de "pequena propriedade rural" não deve ultrapassar 80 ha.

No tocante às APP's situadas no entorno de reservatórios naturais ou artificiais, lagos e lagoas são dispensadas desta exigência as propriedades rurais que conforme Art. $4^{\circ} \S 1^{\circ}$ e $\S 4^{\circ}$ respectivamente, desde que "não decorram de barramento ou represamento de cursos d'água naturais", nem de "acumulações naturais ou artificiais de água com superfície inferior a 1 (um) hectare". Tendo em vista que a maioria das pequenas propriedades rurais do estado (objeto de estudo do presente trabalho) não possui reservatórios de água (açudes, lagos, etc.) com área superior a 1 (um) hectare, as mesmas não precisam recuperar o entorno destes reservatórios, porém não podem realizar novas supressões de floresta nativa nesta área, ou seja, onde possuir vegetação nativa no entorno destes reservatórios, o proprietário esta vedado de retirar a vegetação existente.

No Art. $4^{\circ} \S 5^{\circ}$, que segue, podemos perceber a possibilidade de diferentes usos do solo dentro das APP's em pequenas propriedades rurais:

$\S 5^{\circ}$ É admitido, para a pequena propriedade ou posse rural familiar, de que trata o inciso V do Art. 3-desta Lei, o plantio de culturas temporárias e sazonais de vazante de ciclo curto na faixa de terra que fica exposta no período de vazante dos rios ou lagos, desde que não implique supressão de novas áreas de vegetação nativa, seja conservada a qualidade da água e do solo e seja protegida a fauna silvestre.

Podemos observar, no parágrafo acima, a possibilidade para pequenas propriedades rurais desenvolverem plantios de culturas temporárias (soja, milho, fumo, feijão, batata, mandioca, etc) em APP's, desde que não avancem em novas áreas de vegetação nativa e não prejudiquem o solo, a água e a fauna local. Outra possibilidade que é prevista com a Lei $\mathrm{n}^{\circ}$ 12.651/12 (BRASIL, 2012) para as APP's em pequenas propriedades rurais é presente no Art. $52^{\circ}$ a intervenção e a supressão 
de vegetação em APP's e de RL para as atividades eventuais ou de baixo impacto ambiental, com exceção as alíneas $b$ e $g$, dependendo de simples declaração ao órgão ambiental competente, desde que esteja o imóvel devidamente inscrito no Cadastro Ambiental Rural (CAR).

Além desta utilização, prevista na Lei ${ }^{\circ}$ $12.651 / 2012$, para a pequena propriedade rural, a referida Lei prevê a intervenção e/ou até mesmo a supressão da vegetação nativa nestas áreas em determinados casos como é exposto a seguir:

Art. $8^{\circ}$ A intervenção ou a supressão de vegetação nativa em Área de Preservação Permanente somente ocorrerá nas hipóteses de utilidade pública, de interesse social ou de baixo impacto ambiental previsto nesta Lei.

Nos casos em que as APP's são constituídas por encostas, topo de morros, montes, montanhas e serras com inclinação entre $25^{\circ}$ e $45^{\circ}$, conforme o Art. $11^{\circ}$ :

Serão permitidos o manejo florestal sustentável e o exercício de atividades agrossilvipastoris, bem como a manutenção da infraestrutura física associada ao desenvolvimento das atividades, observadas boas práticas agronômicas, sendo vedada a conversão de novas áreas, excetuadas as hipóteses de utilidade pública e interesse social.

Diante do exposto acima e tendo por base a pequena propriedade rural como objeto de estudo deste trabalho, serão ressaltados apenas os pontos considerados importantes para esta classe no tocante a intervenção e/ou supressão da vegetação nativa em APP's. No CFB, mais especificamente no Art. $3^{\circ}$ inciso VIII, são definidas as atividades que são enquadradas como sendo de utilidade pública, nelas são inseridas inúmeras ações, destacando-se atividades de proteção sanitária, construção de sistema viário. Já as atividades de interesse social, conforme o mesmo artigo, a intervenção e/ou supressão das APP's são previstas no inciso IX para atividades imprescindíveis à proteção da integridade da vegetação nativa como o combate a erosão, proteção de plantios com espécies nativas e exploração agroflorestal sustentável praticada na pequena propriedade ou posse rural familiar ou por povos e comunidades tradicionais, desde que não descaracterize a cobertura vegetal existente e não prejudique a função ambiental da área. Cabe ressaltar a existência de inúmeras outras atividades de interesse social, porém foram abordadas neste estudo apenas as que se mostram importantes para a pequena propriedade rural.

Por sua vez, são definidas ainda no Art. $3^{\circ}$ inciso $\mathrm{X}$ como atividades de baixo impacto ambiental e de importância para a pequena propriedade rural: a construção de moradias de agricultores familiares, construção e manutenção de cercas na propriedade, coleta de produtos não madeireiros para fins de subsistência e produção de mudas (sementes, castanhas e frutos) - observado que no RS a colheita do pinhão só pode ser realizada após o período de 15 de abril até junho (Portaria Normativa DC n ${ }^{\circ} 20$ - IBDF, 1976), plantio de espécies nativas produtoras de frutos, sementes, castanhas e outros produtos vegetais. Isto desde que não implique na supressão da vegetação existente nem prejudique a função ambiental da área.

Uma das principais inovações previstas no CFB é a diferenciação das propriedades antes e após 22 de julho de 2008. Para as propriedades rurais com ocupação antrópica preexistente a referida data e que conforme o Art. $3^{\circ}$ inciso IV possuíam "edificações, benfeitorias ou atividades agrossilvipastoris, admitida, neste último caso, a adoção do regime de pousio", serão consideradas e classificadas como áreas rurais consolidadas, gozando assim dos benefícios estabelecidos e previstos em Lei. Em contrapartida, as que não se enquadrarem nessa classificação, ou seja, que tiveram ocupação antrópica após 22 de julho de 2008, serão classificadas como áreas rurais não consolidadas. A diferenciação temporal entre antes e após 22 de julho de 2008 faz com a Lei, principalmente no tocante as metragens impostas por esta para a preservação e conservação das áreas consideradas de APP e RL, seja aplicada de forma a separar áreas consolidadas e não consolidadas, assim como diferenciar as metragens específicas para cada caso. Contudo, estas definições e conceitos terão importante papel para a interpretação e análise do conteúdo a ser relacionado neste estudo, o que se torna necessário para uma boa compreensão da Lei n ${ }^{\circ}$ 12.651/12 (BRASIL, 2012).

Para as áreas consolidadas, como mencionado no Art. 61-A "é autorizada, exclusivamente, a continuidade das atividades agrossilvipastoris, de ecoturismo e de turismo rural", revelando assim a possibilidade da continuidade do desenvolvimento sustentável de determinadas atividades em APP's para algumas propriedades rurais, porém sem novas conversões. Segundo o Art. 61-A § $1^{\circ}-5^{\circ}$ da referida Lei, para as áreas consolidadas são definidas metragens diferenciadas quando 
comparadas com as áreas não consolidadas, onde a faixa de vegetação varia de acordo com o tamanho da propriedade, ou do imóvel rural como é exposto a seguir:

$\S 1$ Para os imóveis rurais com área de até 1 (um) módulo fiscal que possuam áreas consolidadas em Áreas de Preservação Permanente ao longo de cursos d'água naturais, será obrigatória a recomposição das respectivas faixas marginais em 5 (cinco) metros, contados da borda da calha do leito regular, independentemente da largura do curso d'água.

$\S 2^{\circ}$ Para os imóveis rurais com área superior a 1 (um) módulo fiscal e de até 2 (dois) módulos fiscais que possuam áreas consolidadas em Áreas de Preservação Permanente ao longo de cursos d'água naturais, será obrigatória a recomposição das respectivas faixas marginais em 8 (oito) metros, contados da borda da calha do leito regular, independentemente da largura do curso d'água.

$\S 3^{\circ}$ Para os imóveis rurais com área superior a 2 (dois) módulos fiscais e de até 4 (quatro) módulos fiscais que possuam áreas consolidadas em Áreas de Preservação Permanente ao longo de cursos d'água naturais, será obrigatória a recomposição das respectivas faixas marginais em 15 (quinze) metros, contados da borda da calha do leito regular, independentemente da largura do curso d'água. [...]

Assim, podemos concluir, em relação ao Art. $61-\mathrm{A} \S 1^{\circ}-5^{\circ}$, que anteriormente à data de 22 de julho de 2008, definido pela Lei $\mathrm{n}^{\circ} 12.651 / 12$ (BRASIL, 2012) como "áreas consolidadas", independentemente se houve ou não supressão ou qualquer outra forma de exploração da vegetação nativa em APP ou em outra área protegida por Lei, estas propriedades ficam "livres" de sanções penais e/ou administrativas em resposta ás ações irregulares que por ventura foram realizadas pelas mesmas.

Diante disso, as áreas consolidadas tiveram alguns privilégios, de acordo com suas características (tamanho, de base familiar ou não). Ainda referente ás áreas consolidadas, no caso destas se localizarem em APP's, no entorno de nascentes e olhos d'água perenes, conforme $\S 5^{\circ}$ "será admitida a manutenção de atividades agrossilvipastoris, de ecoturismo ou de turismo rural, sendo obrigatória a recomposição do raio mínimo de 15 (quinze) metros".

De acordo com o Art. $61^{\circ}, \S 6^{\circ}$ e $7^{\circ}$, também são previstas metragens definidas para o entorno de lagos e lagoas naturais, metragens estas diferenciadas de acordo com o tamanho dos imóveis rurais como é exposto a seguir:

[…]

$\S 6^{\circ}$ Para os imóveis rurais que possuam áreas consolidadas em Áreas de Preservação Permanente no entorno de lagos e lagoas naturais, será admitida a manutenção de atividades agrossilvipastoris, de ecoturismo ou de turismo rural, sendo obrigatória a recomposição de faixa marginal com largura mínima de:

I - 5 (cinco) metros, para imóveis rurais com área de até 1 (um) módulo fiscal;

II - 8 (oito) metros, para imóveis rurais com área superior a 1 (um) módulo fiscal e de até 2 (dois) módulos fiscais;

III - 15 (quinze) metros, para imóveis rurais com área superior a 2 (dois) módulos fiscais e de até 4 (quatro) módulos fiscais; $e$

IV - 30 (trinta) metros, para imóveis rurais com área superior a 4 (quatro) módulos fiscais. [...]

Ainda referente às $\mathrm{APP}^{\prime}$ s em áreas consolidadas, conforme inciso $12^{\circ}$ do Art. $61^{\circ}$ percebe-se certa flexibilidade quanto ao uso destas áreas em locais já alterados, porém desde que estes não ofereçam riscos à vida ou à integridade física das pessoas, como observado a seguir:

É admitida a manutenção de residências e da infraestrutura associada às atividades agrossilvipastoris, de ecoturismo e de turismo rural, inclusive o acesso a essas atividades, independentemente das determinações contidas no caput e nos $\S 1^{\circ}$ a $7^{\circ}$, desde que não estejam em área que ofereça risco à vida ou à integridade fisica das pessoas.

Para imóveis rurais que em 22 de julho de 2008 detinham até 10 (dez) módulos fiscais e desenvolviam atividades agrossilvipastoris em APP's em áreas consolidadas, conforme Art. 61-B "é garantido que a exigência de recomposição, nos termos desta Lei, somadas todas as APP's do imóvel, não ultrapassará":

I - $10 \%$ (dez por cento) da área total do imóvel, para imóveis rurais com área de até 2 (dois) módulos fiscais; 
II - 20\% (vinte por cento) da área total do imóvel, para imóveis rurais com área superior a 2 (dois) e de até 4 (quatro) módulos fiscais.

[...]

Podemos verificar que em propriedades com áreas menores que dois módulos fiscais fica garantida (conforme inciso I) que a recomposição da vegetação nativa em não ultrapasse $10 \%$ da sua área total, o que dependendo das características da propriedade, pode fazer com que se reduza ainda mais a metragem prevista em Lei. Para propriedades rurais entre 2 e 4 módulos fiscais também são estipulados no mesmo artigo, recomposição de no máximo de $20 \%$ do total do imóvel.

Com as mudanças ocasionadas pela Lei $\mathrm{n}^{\circ} 12.651 / 2012$, a RL também teve mudanças relevantes principalmente no tocante às áreas consolidadas ou não consolidadas. Conforme conceituação presente no Art. $3^{\circ}$ inciso III da Lei $\mathrm{n}^{\circ}$ 12.651/12 (BRASIL, 2012) a RL é definida como sendo:

III - Reserva Legal: área localizada no interior de uma propriedade ou posse rural, com a função de assegurar o uso econômico de modo sustentável dos recursos naturais do imóvel rural, auxiliar a conservação e a reabilitação dos processos ecológicos e promover a conservação da biodiversidade, bem como o abrigo e a proteção de fauna silvestre e da flora nativa.

Para as áreas rurais não consolidadas, o Art. 12 do CFB (BRASIL, 2012) prevê que todo imóvel rural deva manter uma área com cobertura de vegetação nativa a título de RL, sem prejuízo da aplicação das normas sobre as APPs. No caso da área em estudo, o percentual mínimo exigido para a região de acordo com a legislação é $20 \%$, conforme observado no Art. 12, inciso II da Lei $\mathrm{n}^{\mathrm{o}}$ 12.651(BRASIL, 2012).

Art. 12. Todo imóvel rural deve manter área com cobertura de vegetação nativa, a título de Reserva Legal, sem prejuizo da aplicação das normas sobre as Áreas de Preservação Permanente, observados os seguintes percentuais mínimos em relação à área do imóvel:

[...]

II - localizado nas demais regiões do País: $20 \%$ (vinte por cento).

Para as áreas rurais consolidadas em RL, no Art. 66 da Lei no 12.651/12 (BRASIL, 2012), são definidas diferentes alternativas que podem ser implantadas nas propriedades para assim regularizarem a situação irregular de suas RL's:

Art. 66. O proprietário ou possuidor de imóvel rural que detinha, em 22 de julho de 2008, área de Reserva Legal em extensão inferior ao estabelecido no Art. 12, poderá regularizar sua situação, independentemente da adesão ao PRA, adotando as seguintes alternativas, isolada ou conjuntamente:

I - recompor a Reserva Legal;

II - permitir a regeneração natural da vegetação na área de Reserva Legal;

III - compensar a Reserva Legal.

Para as propriedades que quiserem recompor suas áreas irregulares de RL, conforme Art. 66 (inciso I), nos $\S 2$ e 3 , esta deve ser concluída em até 20 (vinte) anos, sendo que a cada dois anos deve haver uma recomposição mínima de 1/10 (um décimo) da área total, devendo também atender os critérios estipulados pelo Sisnama. Esta recomposição que trata o $\S 2$ pode ser realizada mediante plantio intercalado de espécies nativas e exóticas em sistema agroflorestal sendo que estas últimas não podem ultrapassar $50 \%$ da área total a ser recuperada, porém os proprietários terão direito a exploração econômica destas áreas.

Como este trabalho esta focado às PPR do Médio Alto Uruguai, onde a grande maioria destas se enquadram na classe de pequenas propriedades rurais, ou seja, áreas com até 4 módulos fiscais com ocupação do solo antes de 22 de julho de 2008, conforme Art. 67 do CFB, para as áreas que possuam vegetação remanescente inferior as percentagens exigidas no Art. 12 da referida Lei: "a Reserva Legal será constituída com a área ocupada com a vegetação nativa existente em 22 de julho de 2008, vedadas novas conversões para uso alternativo do solo".

Analisando os resultados obtidos com a vistoria das propriedades em questão e fazendo uma comparação destas com as Leis $n^{\circ} 4.771 / 65$ e $\mathrm{n}^{\mathrm{o}} 12.651 / 12$, nota-se que houve uma redução de $70 \%$ das propriedades em desacordo com o mesmo. Ou seja, na área em estudo o número de propriedades rurais que passaram a estar em dia com a Lei aumentou.

Do ponto de vista legal, o novo Código Florestal reduz o número de propriedades que necessitam algum tipo de intervenção, situação esta vivenciada por uma "anistia" das propriedades que antes de 22 de julho de 2008 já estavam estabelecidas e desempenhavam suas funções. Pode-se 
observar que, como as propriedades analisadas caracterizam-se por possuírem áreas menores que quatro módulos fiscais, ou seja, 80 ha, estas tiveram pouca ou nenhuma mudança no uso do solo em comparação com seus usos atuais.

\section{REFERÊNCIAS BIBLIOGRÁFICAS}

BRASIL, 1965. Código Florestal Brasileiro (Revogado): Lei $\mathrm{n}^{\circ}$ 4.771/65.

BRASIL, 2006. Lei $\mathrm{n}^{\circ} 11.326 / 06$. Disponível em: http://www2.camara.leg.br/legin/fed/ lei/2006/lei-11326-24-julho-2006-544830-normapl.html Acesso: 05/12/12.

BRASIL, 2012. Código Florestal Brasileiro. Disponível em: http://www.jusbrasil.com. br/legislacao/1032082/lei-12651-12 Acesso: 02/12/12.

IBGE, 2006. Número de estabelecimentos agropecuários. Disponível em: http://www.ibge.gov. br/estadosat/temas.php?sigla $=$ rs\&tema $=$ censoagro Acesso: 05/12/2012.

COREDE 2012. Proposta de Agenda de Desenvolvimento Médio Alto Uruguai: Programa de Combate às Desigualdades Regionais. Disponível em: http://www.fee.tche.br/ sitefee/pt/content/resumo/pg coredes detalhe. php? corede $=\mathrm{M} \% \mathrm{E} 9$ dio + Alto + Uruguai Acesso: 03/06/2012.

FEPAM, 2013. Regiões hidrográficas do RS http://www.fepam.rs.gov.br/qualidade/ regiao uruguai.asp Acesso: 17/02/13

INCRA, 1980. Módulo Fiscal de cada Município, previsto no Decreto ${ }^{\circ} \mathbf{8 4 . 6 8 5}$ de 06 de maio de 1980. Disponível em: http://www.canalrural.com.br/pdf/11097027.pdf Acesso:18/02/13.

PIRAN, N. Agricultura familiar: lutas e perspectivas no Alto Uruguai. Erechim: EdiFAPES, Série Pensamento Acadêmico 11, 192p., 2001. RÜCKERT A. A. et al. A construção do território na região de Ronda Alta: ocupação e colonização: 1831-1996. Porto Alegre: Secretaria Municipal de Educação e Cultura de Ronda Alta, 1999.

STRECK, E.V.; KÄMPF, N.; DALMOLIN, S.D.R.; KLAMT. E.; NASCIMENTO. C.P.; SCHNEIDER, P.; GIASSON, E.; PINTO,F.S.L. Solos do Rio Grande do Sul. 2.ed. Porto Alegre: EMATER/RS-ASCAR, 222p. 2008.

IBDF, 1976. Portaria Normativa DC-20 de 27/09/1976. Disponível em: http://www.ipef. $\mathrm{br} /$ legislacao/bdlegislacao/detalhes.asp? $\mathrm{Id}=280$ Acesso: 12/06/2012. 